\title{
Developments in International Financial Reporting Standards and Other Financial Reporting Issues
}

\author{
Jonathan Bloomer \\ Prudential plc, UK. \\ E-mail: DavidC.Martin@Prudential.co.uk
}

This paper addressess the impact of the implementation of the new international reporting standards on insurance companies.

The Geneva Papers (2005) 30, 101-107. doi:10.1057/palgrave.gpp.2510002

Keywords: financial reporting standards; IFRS 4; IASB; phase I and II

\section{Introduction}

The life insurance industry finds itself at the centre of increasingly turbulent times as regards financial reporting. In particular, with the implementation of International Accounting Standards by the European Union and a number of regulatory developments, the level of change with which senior management of the major companies are confronted continues to be extremely onerous. To make matters even more challenging, much of this change is already expected to be transitionary, with further proposals expected in the future.

The changes may have effects on a number of areas with consequences for strategic issues, capital, and other fundamental issues. The canvas for these changes is broad. However, this paper seeks to address the specific issues arising in the opaque, but important, area of the financial reporting framework that will apply for the European insurance industry for 2005, and to report the possible direction of future changes and the likely impact of these developments.

\section{Background}

The changes for statutory basis reporting in 2005 primarily result from the anticipated adoption of IFRS by the European Union (EU). It is therefore expected that for 2005 reporting the consolidated accounts of EU listed insurance groups will be prepared in accordance with IFRS. Accounts prepared on this basis will replace the previous basis that has been in place since the mid-1990s when the Insurance Accounts Directive was implemented into member state legislation.

There remains no consensus on an appropriate longer term basis of reporting for insurance in companies' main financial statements. Consequently, for 2005 and the immediate future, companies' statutory basis results will reflect the compromise Phase 1 requirements of the International Accounting Standards Board (IASB). 
102

The issues involved in developing a comprehensive Phase 2 solution are unlikely to be resolved for some time. The IASB has indicated that it has a target deadline for a comprehensive Phase 2 insurance standard of 2007. However, it seems likely that this target date is ambitious. Indeed, some commentators have speculated that the chances of a Phase 2 standard being in place much before 2010 are low.

The IASB is now in the process of reactivating its Phase 2 programme and it is essential that the industry remains fully engaged in the development stage and actively puts forward its own proposals: it is important that the industry says what it is for, not just what it is against.

The 2005 requirements and their impact, together with an indication of the likely Phase 2 issues, are summarized below.

Although the detail of the IASB's Phase 1 requirements has taken a long time to mature, the finance teams of the major European insurers have known of the expected generic features and their drawbacks for some time. In addition, there has in the last year or so been an increased recognition of a need for a common codified approach to the determination of value-based results, which all major European insurers now report as supplementary basis information. It has also become increasingly clear that such codification should include enhancements so as to improve the basis of calculation for the economic impact of guarantees and option features in insurance contracts and to improve disclosure.

In response, the major European insurers, under the auspices of the CFO Forum, have developed a set of common principles for European Embedded Value (EEV) basis reporting to be applied from 2005. The key features of this development are described later in this paper.

In addition to the accounting developments summarized above, the European Commission issued in February 2004 a consultative document on the possible shape of Solvency II requirements. In broad terms, the proposals envisage that Solvency II will, as far as possible, reflect the accounting framework and that by the time Solvency II is implemented that framework will reflect the IASB's Draft Statement of Principles (DSOP) approach to liability measurement. Some high-level observations are noted later in this paper.

Finally, this paper seeks to draw together some common themes that will continue to be pervasive as the reporting regime develops.

\section{IFRS basis reporting}

Owing to difficulties encountered in developing a standard for insurance contracts, the requirements put in place by the IASB in the standard IFRS4, which was issued in March 2004, represent a temporary mechanism for accommodating current GAAP accounting for most insurance contracts.

The plans set out in IFRS4 are relatively modest in comparison with the overhaul of insurance accounting envisaged under Phase 2. According to the IASB, this initial phase is designed to make "limited improvements to accounting practices" and provide "key insights into the key risk drivers and sensitivities of insurance contracts". 
IFRS4 can give rise to two particular anomalies to reported results. These are:

- the asset/liability mismatch issue due to differing valuation bases for investments and insurance contract liabilities; and

- the deposit floor constraint on valuing liabilities of contracts that do not contain significant insurance risk.

It is inevitable that these anomalies will lead to increased volatility in reported earnings. While the IASB recognized these anomalies there was insufficient time to resolve them other than a partial solution using flexible discount rates in valuing liabilities.

In general terms, given the effect of these anomalies and the differences between local GAAP reporting in different member states, it seems highly likely that the IFRS basis results reported by European insurers in 2005 will not be comparable with the results of other industries or between each other. Furthermore, to the extent that local GAAP bases for liability measurement reflect a solvency-based approach, the currently opaque representation of financial performance will remain embedded in the IFRS basis results.

In re-activating the IASB's work on Phase 2 proposals, the starting point will be the DSOP. The DSOP represents the culmination of the work of the IASB's predecessor body, the International Accounting Standards Committee (IASC). The IASB started discussing the DSOP in November 2001 but it was not approved. The DSOP, which advocated a "fair value" approach to liability measurement, attracted considerable opposition from the insurance industry.

In formulating its own proposals the insurance industry will need to re-address some core issues about the broad nature of the model to be applied. Model options to consider might include IASB "fair value", embedded value, asset/liability, deferral and matching (as applied in much of current insurance GAAP) or a mixed attribute model. Consideration should also be given to whether the same model should apply for life and non-life business and short- and long-term contracts.

\section{Embedded value basis reporting}

On 5 May 2004 the CFO Forum published a set of principles for embedded value calculations and disclosure, entitled "European Embedded Value" (EEV). Members of the CFO Forum have each committed to adopt the principles for supplementary EV reporting by no later than 2005 for full year results. The aim of this standard is to address some of the perceived weaknesses in traditional EV reporting. These weaknesses might be summarized as:

- variability in both the EV calculation processes between different companies and assumptions used;

- a lack of a common international standard for EVs;

- lack of a standard format for disclosing EVs and varying levels of detail in disclosure hindering transparency;

- an inadequate allowance for "asymmetric risks" in life product options and guarantees; 
- the fact that EVs can increase simply owing to a move to a "riskier" asset mix (all other things being equal); and

- the problem of using a "blended" discount rate across different products and cash flows when the risk profile of each may differ widely.

In general terms, the EEV principles provide a common framework for incorporating an allowance for risks inherent in insurance contracts for determining the value of future cash flows from in-force long-term business. The principles also provide a common standard for disclosure of the EEV results, basis of preparation, and sensitivities.

Companies, though, are allowed a degree of flexibility as to the types of business valued under EEV principles, and the determination of the precise allowance for risk is at companies' discretion rather than being dictated through a set of detailed rules.

Market reaction to the proposals could perhaps be summarized as follows. On the positive side,

- They provide a significant step forward in improving consistency, transparency and disclosure of EV calculations.

- The use of stochastic modelling techniques to capture the time value of "out of the money" options is helpful and it is likely to lead to lower disclosed embedded values.

- The required disclosures over methods and assumptions and new business margins should aid comparability.

- EEV should give rise to better disclosure over the amounts of solvency capital allocated to life business.

- Adoption of EEV should give rise to better disclosure over "embedded value profit".

On the negative side, the concerns of analysts, which were anticipated when the principles were drawn up, are

- The principles do not require "market consistent" EV calculations. This could allow insurers to continue with some discretion over their allowance for market risk and asset/liability mismatching.

- There will continue to be variety and inconsistency between companies in the allowance for risk. Disclosure though should allow analysts to flex companies' results to some degree to improve comparisons.

On balance, the reaction has been broadly positive and the CFO Forum's work recognized as helpful.

It should be noted that on the principal new feature of EEV, namely the valuation of guarantees, there is a clear distinction between the stochastic basis under EEV and the basis envisaged by the IASB as part of its DSOP proposals.

Under EEV the mean assumed rate of future investment return, around which stochastic projections are centred, reflects the assumptions used elsewhere within the cash flow projections for future investment returns. Thus, the stochastic projections will include benchmark long-term returns for equities, bonds, properties and so on.

These assumed rates are in turn, generally speaking, reflective of current bond yields and assessments of risk margins for the particular type of investment. This is to be 
contrasted with so-called "market consistent" bases of projecting investment returns, as reflected in the DSOP and which some analysts would like to be provided as additional information.

This difference of approach is likely to be a recurring theme as the IASB develops its Phase 2 proposals and market reaction to EEV basis results.

\section{Solvency II: Regulatory basis reporting}

In February 2004 the EU Commission issued a consultation paper on the possible direction of the Solvency II proposals.

Two points are perhaps worth noting as to the overall approach by the EU.

\section{Premise of consistency with IASB basis reporting}

Issue 1 of the paper asks for views on the proposed way of integrating the IASB insurance Phase 2 accounting into the Solvency II project. This is based on the premise that the Solvency II project should be IASB compatible in order to reach a greater level of harmonization. This in turn seems to be based on a premise that IASB's Phase 2 proposals are a relatively fixed reference point.

As noted above, though, the IASB, in developing its DSOP that formed the initial proposals for the intended Insurance Standard, encountered considerable opposition at both the theoretical and practical level.

At the theoretical level, the merits of the "asset and liability" approach and a host of very substantial technical conclusions were not accepted by a wide range of informed commentators and major insurers. In addition, on certain key areas, the DSOP proposals were either tentative or not developed at all. There is no general consensus that a basis that has its roots in the DSOP approach is suitable for general purpose financial statements.

On the contrary, as mentioned above, there is an opportunity during the Phase 1 period, to reconsider whether the proposals on the eventual Phase 2 standard should be constructed on different building blocks. Whether this is on the lines of a deferral and matching approach, an asset and liability model, or some form of mixed attribute model will require considerable discussion.

Given that the Phase 2 debate has yet to be properly reactivated, the EU's supposition that the accounting framework will reflect the DSOP approach seems premature. As an aside though, it is in keeping with the "realistic" basis of reporting liabilities being developed in the U.K. and perhaps is indicative of the general direction in which regulatory reporting can be expected to develop.

\section{Harmonization}

The intention of the Commission is to move to a higher degree of harmonization than currently applies. While this broad objective is laudable there are potential pitfalls that need to be carefully addressed. While acknowledging the trade-off issues between overly rule-book based and high-level principles approaches, we should not 
lose sight of two key objectives that the Solvency II proposals must meet to be acceptable.

First, the proposed approach must be equivalent at the level of practical application by member state regulators as well as by theoretical equivalence. The development of the Solvency II proposals should be accompanied by the establishment of an appropriate process to ensure consistent practical application that is transparent to those who prepare regulatory basis information.

Secondly, processes need to be developed so as to ensure that member state regulators default to applying only the requirements of the directive. The application of more onerous superequivalent approaches should be permitted only under defined circumstances which are, as part of the EU mechanisms, subjected to explicit validation that the harmonization principle has not been impaired in its practical application. In other words, the Solvency II proposals should reflect the only standard, not the minimum standard.

\section{Overall conclusion}

The likely impact of IFRS on the 2005 results will inevitably depend on the circumstances of individual companies. However, setting aside the asset/liability mismatch and deposit floor concerns, the overall initial impact can be expected to be considerably less than would be expected under the IASB's original DSOP proposals.

The direction of the Phase 2 proposals has yet to be established but it will be a challenge for the insurance industry to achieve a solution that better reflects the economic position and at the same time fits in with the IASB's framework. The CFO Forum has moved to improve the way in which companies will demonstrate this economic position from a value perspective - so as to align more fully with the way the business is run - by the adoption of the EEV principles for supplementary reporting.

The challenge now is to develop a set of coherent proposals in the context of the primary financial statements. Intuitively companies may prefer a mixed attribute model that reflects the best aspects of a deferral and matching method, with some allowance for guarantees, but the theoretical merits will need to be well articulated to gain acceptance.

Regulatory developments suggest that it will be difficult to resist EU pressure to adopt something akin to the DSOP approach and this should form an important second strand to the efforts of the major insurers to influence the debate.

It is important that the debate is not seen as a European one. As the IASB itself points out it is an international standard setter, but in recent months the debates over IFRS and IAS39 have concentrated perhaps too much on the European dimension because of the time pressures imposed by the European Commission's 2005 deadline.

The Phase 2 proposals can be considered over a longer timeframe, but one that will still require steady progress, in which it is important that all areas of the insurance industry, life, general, and reinsurance, are represented by practitioners from all markets, not just Europe. The Geneva Association has an obvious role to play in promoting this participation. 
In more general terms, the future developments can be seen as part of a series of changes that may have significant consequences on financial and regulatory reporting. In turn, these changes may have consequences in a number of areas. In summary, the issues would be:

- An increased focus on the financial effects of products that include guarantees or require a high level of capital support.

- An uncertain future for the perceived profitability of participating business.

- The obscuring of the underlying profitability of new business, if the IASB DSOP approach prevails.

- The increased focus on the management of risk, in particular ALM strategies. While this may be welcome, there is a general sense that the accounting regime should not give rise to inappropriate asset allocation to avoid volatility in published results.

- A fundamental change in regulatory reporting, which may have profound effects on the level of capital flexibility of companies.

The financial reporting regime will continue to be subject to continued fundamental change for some time. In addition to affecting our own individual company positions, it presents a considerable challenge for the industry as a whole to explain its financial position. 